\title{
Teaching Exploration of Parasitology Test under the Guidance of Big Data
}

\author{
Ying Liu, Yan Zhao, Hongjuan Song, Fengying Zheng, Yuchan Guo \\ Department of Medicine, Binzhou Polytechnic, 256603, China \\ Email: 359292773@qq.com
}

Keywords: Big Data; Moso Teach; Teaching Feedback

\begin{abstract}
The information platform of Moso Teach can provide teaching support with a big data. This article discusses how to use teaching report data, teaching resource data, teaching activity data, learning situation data and artificial intelligence to generate accurate feedback to the problems and difficulties in teaching, guide teachers to adjust more targeted teaching content, offer more specific coaching to individuals and therefore improve teaching efficiency. Material of Moso Teach can also be used as an objective basis for evaluating teaching quality.
\end{abstract}

\section{Introduction}

Today, with the rapid development of information technology, the internet+ has entered all walks of life, and its application in the field of education has gradually developed. However, most information teaching platforms do not pay attention to the function of data analysis. The teaching platforms become a platform of resource display. The learning situation of students is still obtained by traditional methods.It is not objective, incomplete and not timely.

Moso Teach is a real-time interactive teaching assistant in mobile environment [1], one of its characteristics is to carry out detailed data statistical analysis of each activity to accurately guide teaching.

"Parasitology test" is a core course of medical examination technology major. The content of the course is simple and easy to understand, but the knowledge points are in a large number and scattered, and students often cannot understand thoroughly. Traditional teaching is is limited by time, so whether students can grasp the morphological characteristics and whether they can distinguish the details of the structure, can only be known through individual assessments and questions, which cannot accurately reflect the learning status of most students. Teachers cannot teach students according to their aptitude and cannot provide individualized guidance. Therefore, we adopted Moso Teach this new teaching mode, make full use of the statistical analysis function of Moso Teach to get accurate learning statistics of all the students, understand the learning status of each student, and guide teachers to explain the teaching emphasis and difficulties, respond to differentiated learning needs and improve teaching efficiency [2].

\section{Feedback effect of teaching report}

The teaching report of Moso Teach will count student members, the learning resources, learning activities such as tests, group assignments, brainstorming, voting questionnaires, discussion and answering questions, etc. Whether the diversity of activities is reasonable, which are used well and not fully utilized can be clearly seen by teachers. In the teaching process, Moso Teach will give a weekly report to show whether teaching activities can be fully carried out during those periods. The total number of resources and activities and the number of new ones will be clearly presented in the form of graph and histogram (as shown in figure 1). Teachers introspect themselves whether they are in a positive working state through the numbers. 


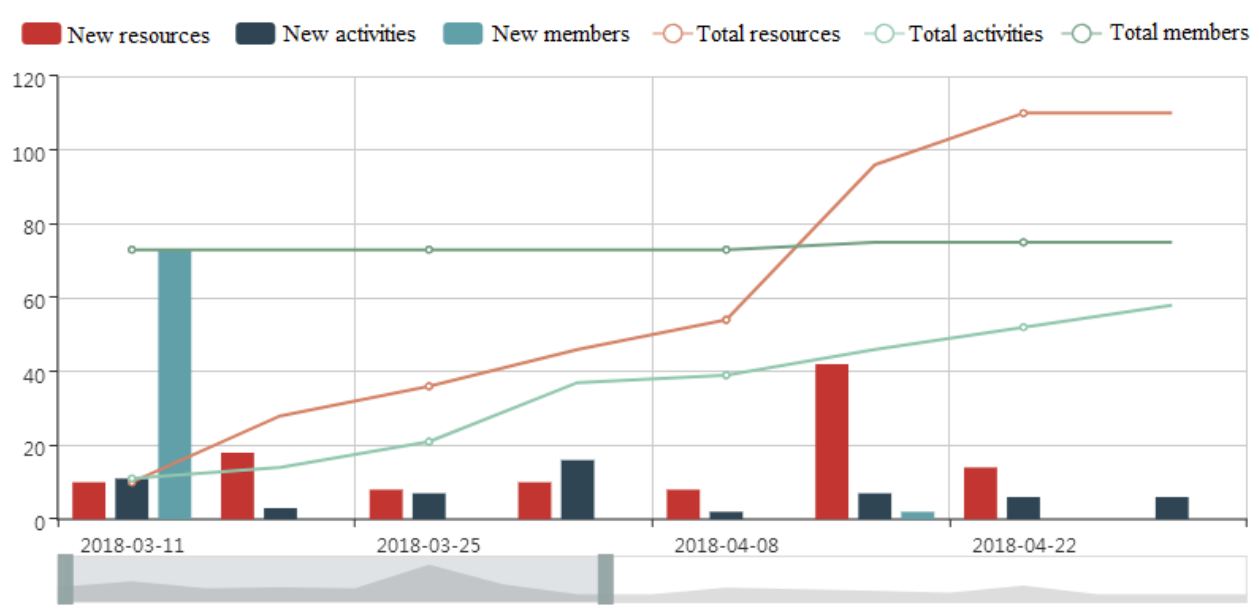

Figure 1 Weekly report of teaching

\section{Feedback effect of teaching resource data}

The teaching of Moso Teach is dominated by students' learning,g, and the role of teachers becomes "guidance" [3]. But the role of teachers has not been weakened, but leading role is even more important. Students' self-directed learning is required and not random. Teachers should design guidance materials in advance according to their teaching objectives and provide a large number of students' favorite learning resources. Whether these types of resources are single, whether the students have studied, whether they have finished, and when they have learned, Moso Teach will count each student's learning resource composition and summary data, facilitate teachers to track each student's learning process, timely to remind individual students complete the learning task, and to arrange the release time reasonably.

\section{Feedback effect of teaching activity data}

\subsection{Check-in Activities}

Moso Teach designed two sign-in methods, a quick one-click check-in and a hand gestures check-in to prevent cheating. After signing in, Moso Teach can immediately put the list of students who are not in attendance at the top. Students who are not in attendance can ask for reasons through private chat, give warnings, and record them in Moso Teach for convenience of checking. Moso Teach can also give a long-term attendance rate, so that teachers can master the attendance of the whole class. With this attendance method, the attendance rate is greatly improved.

\subsection{Feedback effect of teaching activity data}

Moso Teach can make a statistical summary of the finished teaching activities, analyze the proportion of teaching activities (as shown in Figure 2) and the participation of students. Teachers can adjust and improve the teaching activities with poor participation. According to the analysis of Figure 4, the activities of discussion and answering questions are few and students' participation is low. This reflects a common problem in the learning process of students that the learning initiative is poor. Although the test results are not satisfactory and group work errors emerge in an endless streams, students do not actively participate in the discussion and do not ask much questions. Students are accustomed to passively accepting knowledge and cannot make full use of channels when they have. This shows the important guiding role of teachers, and it should be specific. Teachers can check the students' mind map of preview homework, put the problems found into the discussion and answer questions, and guide students to participate. 


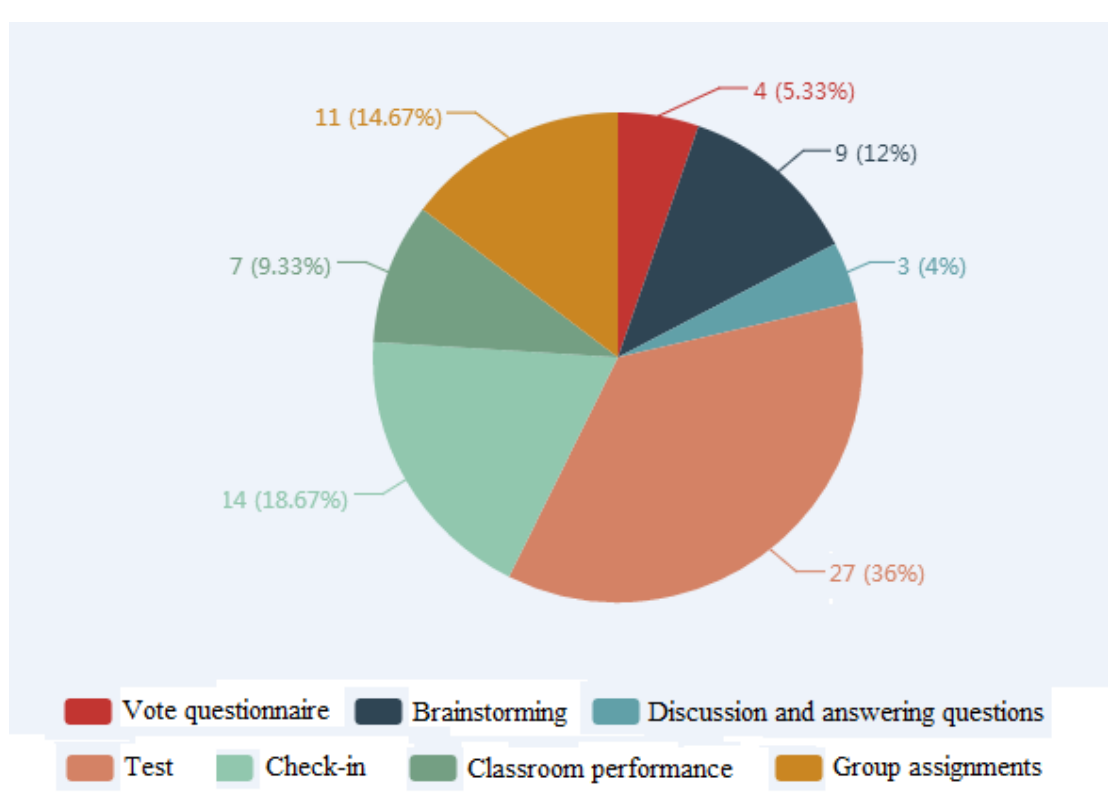

Figure 2 Composition of teaching activities

After the test activity, Moso Teach will automatically make statistics on the scores, and students' time, score ranking, average score, standard deviation, score distribution of each score segment, correct rate of each question and percentage of each option(as shown in figure 3). According to these data, we can understand the overall learning status of the class, and accurately choose the key content to explain. Teachers can also easily view the result analysis of a single student and learn about the ups and downs of his learning.

Overall situation(Percentile system)

\begin{tabular}{|c|c|c|c|}
\hline Highest score & Lowest score & Average score & Standard deviation \\
\hline 89.19 & 54.05 & 77.88 & 8.35 \\
\hline
\end{tabular}

Score segment distribution (Percentage system, every 10 points in a bar)

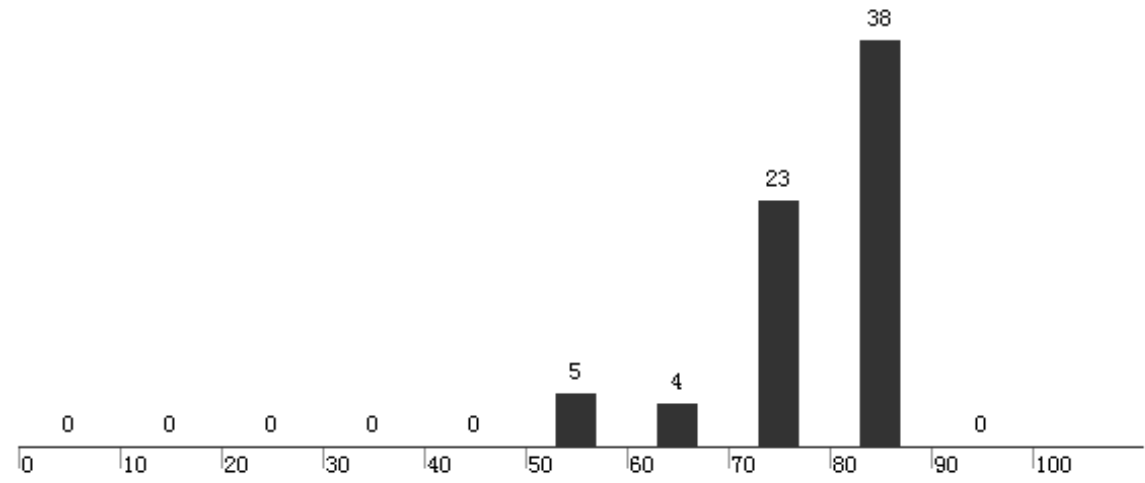

Figure 3 Analysis of a test score

The voting questionnaire activities was conducted using an anonymous questionnaire. All students can truly express their own problems and opinions, help teachers to understand the students' preferences, learning difficulties and teaching suggestions. It is truly achieve a comprehensive, objective and timely manner that guides teachers to adjust the teaching content and emphasis.

\section{Feedback effect of learning situation data}

The experience values obtained by students in Moso Teach can reflect the learning status of the whole class of students. Teachers analyze the way to obtain the experience values, so as to facilitate 
to reasonably adjust the distribution of experience values at the end of the term and to weighte the scores.

Moso Teach also specifically analyzes the differences between students with low experience value and outstanding students in various aspects (as shown in figure 4) to guide teachers' personalized coaching.

01-08Lin Bo $\square$ Outstanding student $\square$ Average experience value of student

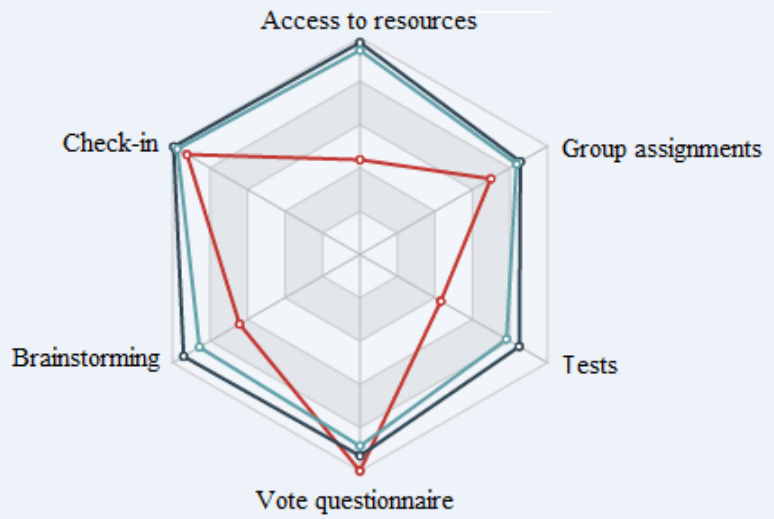

Figure 4 Analysis with lower experience value student

\section{Accurate feedback of artificial intelligence}

Moso Teach not only has the teaching support of big data, but also develops the artificial intelligence "small ink" of the teacher side. Every week, small ink will inform the teachers who have lower attendance and who are fall behind, and remind teachers to give more concerns to them and to offer praise to students with improved grades. It will also reminds teachers to explain questions with a low correct rate in detail. When the activity is single, it will suggeste to carry out various types of activities to mobilize the enthusiasm of the students. When the activities are rich, the teachers are encouraged.

\section{Effect on teaching evaluation}

Traditional teaching evaluation often focuses on results and ignores processes, and the evaluation system is unreasonable and becomes a mere formality. Moso Teach can keep the teaching resources, teaching management and teaching activities prepared by teachers in the whole course for a long time. These teaching process data can be used as an important objective reference index to evaluate the teaching quality of teachers. With the change of teaching model, teaching evaluation should also keep pace with The Times, so as to fully mobilize the enthusiasm of teachers to participate in the teaching reform [4].

\section{Limitation of Moso Teach statistics}

The statistics of Moso Teach can provide objective reference for teachers, but some activity data does not fully reflect the real state of all students. For example, some only open the file to get experience value, and do not really study resource [5]. Some skip classes in the middle. Some copy other people's answers in test and brainstorm. In the discussion and answer, some upload the same speech repeatedly in order to gain the experience value. Brainstorming, discussion and answering activities do not allow for more detailed intelligent statistics. The assignment can not be graded automatically. All these are to be further improved in the future development and application of technology. 


\section{Conclusion}

In the information age, the statistical function of big data is increasingly prominent. Moso Teach can provide detailed and accurate teaching resource data, teaching activity data and learning situation data, so that teachers can timely understand students' learning status and learning difficulties, make targeted adjustment of teaching content, and provide personalized follow-up guidance to improve teaching efficiency. At the same time, it provides a procedural objective basis for teaching management and teaching evaluation.

\section{Acknowledgement}

In this paper, the research was sponsored by Project of Scientific Research of Binzhou Polytechnic (Project No. 2013XYKT121).

\section{Reference}

[1] Aiping Qi. Discussion on the application of Moso Teach in teaching process. China Computer and Communication [J], 2016(19):207-208.

[2] Jie Fu.The reform and practice of real-time interaction class under the reconstruction of cloud class. Journal of Zhejiang Institute of Ommunications[J], 2017,18(3):50-54.

[3] Mengya Chi.The impact and challenge of mobile intelligent terminals on traditional teaching methods. Heilongjang Science and Technology Information [J], 2017(18):167-168.

[4] Xiaoling Guo, Renjie Wu, Puyan Li, et al. Application and data analysis of Cloud class in mobile teaching.Journal of Hebei North University [J], 2018(2):111-116.

[5] Lei Yu, Leiyan Yu, Zhongna Yu, et al. A preliminary study on the procedural evaluation of the implementation of Moso Teach in animal physiology. Shandong Journal of Animal Science and Veterinary Medicine [J], 2017(38):86. 